\title{
Clients and Clinician Satisfaction with Laboratory Services at the National Referral Hospitals of Eritrea
}

\author{
Filmon Hagos ${ }^{1}$, Yacob Tesfamichael ${ }^{2}$, Efrem Ghirmay ${ }^{3}$, Abraham Teklu ${ }^{4}$, Solomon Negash ${ }^{5}$, \\ Oliver Achila ${ }^{6}$ \\ 1 Clinical Laboratory Service Unit, Eritrea Ministry of Health, P.O. Box 212 Asmara, Eritrea \\ 2 Clinical Laboratory Science, Asmara College of Health Sciences. \\ 3 Clinical Laboratory Science, National Drug Quality Control Laboratory \\ 4 Clinical Laboratory Science, Halibet National Referral Hospital Laboratory \\ 5 Clinical Laboratory Science, Orotta National Referral Hospital Laboratory \\ 6 Clinical Laboratory Science, Department Asmara College of Health Sciences \\ *Corresponding Author: Dr. Filmon Hagos Clinical Laboratory Service Unit, Eritrea Ministry of Health, P.O. Box 212 Asmara, \\ Eritrea. \\ Email: filhagos68@gmail.com; Tel: +2917334855
}

Received: June 30, 2021; Accepted: July 18, 2021

\begin{abstract}
Objective: The objective of the study was to assess clients' and clinicians' satisfaction with laboratory services in specific hospitals in Asmara, Eritrea. Results: In general, data was collected from 371 patients who had received laboratory services and 58 clinical service providers. The pooled satisfaction rating was $74.1 \%$. The lowest $(65 \%)$ and highest $(100 \%)$ level of satisfaction were on cleanness of latrines and language of communication. Satisfaction rating was significantly associated $(p<0.05)$ with level of education, occupation, residence and hospital. Laboratory services offered at Orotta hospital had a higher rating $210(87.1 \%)$ vis-a-vis that of Halibet hospital $65(50 \%)(P<0.000)$. Most of the clinical services providers were satisfied (85.3\%) with the services.
\end{abstract}

Keywords: Patient Satisfaction, Clinician Satisfaction, Eritrea.

\section{INTRODUCTION}

Delivery of optimal clinical laboratory services requires much more than just one or two simple measures, but an integrated range of strategies including adequate staffing and training, range of diagnostic technologies, equipment, supplies, reliable quality assurance and control standards, and adequate number of laboratory services, among others. Accomplishing these is dependent on a multiplicity of factors including the substantive public or private sector investment in laboratory infrastructure. In spite of the widespread recognition that adequate funding of laboratory services within a country is a vital pillar in health service provision; availability and access to quality clinical laboratory services is a major challenge in much of Sub-Saharan Africa (SSA).

The barriers to adequate provision of clinical laboratory services are particularly acute at peripheral laboratories. Systematic assessment of laboratory services within a country has been proposed by several agencies ${ }^{[1,2]}$. A critical tool which has been employed in this regard involves surveying patient-satisfaction levels. The importance of this tool is underscored by the fact that the College of American Pathologists and the Joint Commission on Accreditations for Healthcare Organizations requires all laboratories within its jurisdiction to undertake customer satisfaction surveys either to obtain of maintain accreditation [2, $3,4,5]$. These studies have also gained popularity and usefulness due to the fact that they can uncover useful feedback which may be instrumental in uncovering the gap between the expected and perceived characteristics of services [6]. Moreover, it has been suggested that repeating studies bi-annually can be useful in maintaining quality of laboratory service and enhancing health care provider's accountability ${ }^{[7]}$.

Although the importance of these surveys is well recognized, less attention has been paid to these studies in much of SubSaharan Africa. This fact is adequately exemplified by the paucity of studies on satisfaction with primary customer groups. Indeed, the reliance on technical and functional reports of outcome prevails in most settings ${ }^{[8,9]}$. A similar situation prevails 
in Eritrea. The country has a rapidly evolving clinical laboratory service landscape. However, this development is inadequately informed by feedback from customers or physicians. This study therefore was designed to assess the level of clients and clinician satisfaction with clinical laboratory services offered at two referral hospitals in Asmara, Eritrea.

\section{MAIN TEXT}

\section{Study design and Setting}

A cross-sectional study was conducted from May-September 2020 to assess the level of clients and clinician's satisfaction with laboratory services at the Orotta and Halibet National Referral Hospitals, in Asmara, Eritrea. The two institutions are the only medical surgical national referral hospitals in the country and, thus offer services to patients countrywide. Briefly, Orotta has several departments including medical-surgical, pediatric, maternity and Internal medicine department. The hospital has 600 technical staff and 429 administrative staff. Similarly, Halibet hospital has surgical, orthopedic, internal medicine, trauma, burn and dermatology units. The laboratory services provided by these hospitals include Parasitology, Bacteriology, Clinical Chemistry, Immuno-serology, Hematology, and Blood Banking. Further, the hospital has 349 technical and 118 administrative staff. Orotta hospital laboratory had average of 94,000 patient flows every year, while Halibet hospital had average of 54,000 patient flows every year.

\section{Study population}

Clinical service providers within the two institutions were included in this study. In addition, randomly selected patients were recruited. Selection criteria included patients above 18 years of age, patients utilizing laboratory services, willingness to grant consent. Seriously ill patients were excluded from the study.

\section{Sample size and sampling technique}

The sample size determination was based on the level of precision required for the proportion of clients who were satisfied with the laboratory services in those facilities. Cochran's formula was used to estimate the sample size ${ }^{[10]}$. A satisfaction level of $50 \%$ (p) was used in the sample size determination. A 5\% points of absolute precision $95 \%$ confidence interval was used. A total of 371 were enrolled in the study.

\section{Collection of data from Patients}

Data was collected using structured questionnaire. The questionnaire incorporated several questions on sociodemographic characteristics and patients 'satisfaction indicators toward medical laboratory services. A 5-point Likert Scale rating of Poor (1-point), Fair (2-points), good (3-points), very good (4points) and excellent (5point) was used to score satisfaction ratings for laboratory services. Initially, the questionnaire was prepared in English and was subsequently translated into Tigrinya (Eritrea National Language). The questionnaire was administered to patients who had finished their laboratory examinations and returned to Out Patient Department (OPD).

\section{Collection of data from clinical service providers}

A self-administered English questionnaire was given to physicians. The questionnaire contained specific parameters including socio-demographic characteristics, and different clinicians' satisfaction indicators toward medical laboratory services.

\section{Statistical analysis}

Data entry and analysis was made using SPSS 20 software. Poor and fair responses were considered as dissatisfied, where as good, very good and excellent were considered as satisfied. Clients with neutral rating responses were excluded. The percentage satisfaction or dissatisfaction was calculated by dividing the number of satisfied or dissatisfied responses by the total number of respondents excluding neutral response rating, respectively.

The overall rate of satisfaction by Likert scale was calculated as (No. of excellent rating $\times 5)+($ No. of very good rating $\times 4)+($ No. of good rating $\times 3)+($ No. of fair rating $\times 2)+($ No. of poor rating $\times 1)$ divided by the total number of ratings (1-5) for the specific laboratory service. While the percentage of excellent, very good, good, fair or poor rating was calculated by dividing the number of excellent, very good, good, fair or poor rating by the total number of ratings (1-5) for specific laboratory service, respectively. Association of the variables was checked using Chi-square test. Univariate and multivariate logistic regression is employed to determine the possible socio-demographic characteristics associated with the level of satisfaction. Pvalue $<0.05$ was considered as statistically significant.

\section{Ethical Clearance}

The proposal gets ethical clearance from the Ministry of Health, Eritrea, and research ethical committee. Written consent was obtained from all the participant in this study.

\section{RESULTS}

Socio Demographic characteristics of the participant: A total of 371 patient and 58 clinical service providers were recruited in the study. Among the study subjects, $170(45.8 \%)$ of the patients were males and the rest were females. Majority of the respondents were government workers146 (39.4\%). Housewives and casual laborers comprised, 71 (19.1\%) and $60(16.2 \%)$, respectively. Disaggregation of data with respect to age revealed that $111(29.9 \%)$ of the participants were less than 25 years of age, 107 (28.8\%) were 25-40 years of age; 109 $(29.4 \%)$ of were within the $40-60$ years age grouping; and 44 $(11.9 \%)$ were above 60 years of age. Similarly, $158(42.6 \%)$ of the respondents attained secondary school and $59(15.9 \%)$ had college level qualification. About 272(73.3\%) of the respondents were residents of Asmara, while the rest 99(26.7\%) were nonresidents. (see Supplementary Table 1). 
Table 1: Level of satisfaction of respondent with different measuring item of laboratory services in both hospitals (371).

\begin{tabular}{|l|l|l|}
\hline Variables & Satisfied & Dissatisfied \\
\hline Location of the lab & $338(92.3)$ & $28(7.7)$ \\
\hline Cleanness and attractiveness of the laboratory room & $356(96.2)$ & $14(3.8)$ \\
\hline Availability of laboratory staff on working hours & $351(94.9)$ & $19(5.1)$ \\
\hline The cost of the laboratory service & $199(68.9)$ & $90(31.3)$ \\
\hline Willingness to conduct laboratory investigation & $357(98.1)$ & $7(1.9)$ \\
\hline Conduct of laboratory staff during specimen collection. & $355(96.7)$ & $13(3.5)$ \\
\hline Waiting place & $253(70.5)$ & $106(29.5)$ \\
\hline Information given during specimen collection & $250(68.1)$ & $117(31.9)$ \\
\hline Location of latrine to collect specimens & $239(70.9)$ & $98(29.1)$ \\
\hline Cleanness of toilet to collect specimens & $214(63.5)$ & $123(36.5)$ \\
\hline Length of time to take results back to physician & $284(77.8)$ & $81(22.2)$ \\
\hline Language of laboratory staff used to communicate & $357(100)$ & \\
\hline Overall satisfaction & 74.1 & 25.9 \\
\hline
\end{tabular}

In Likert Scale, Poor and fair responses were considered as dissatisfied, whereas good, very good and excellent were considered as satisfied. The proportion of satisfied patients is illustrated in Table 1. The pooled satisfaction rating was $74.1 \%$. The item with highest rating was language utilized in the laboratory.

Table 2: Bivariate and multivariate analysis predictor to assess the socio-demographic variables with the satisfaction of patient at the national referral hospitals.

\begin{tabular}{|c|c|c|c|c|c|c|}
\hline Risk Factors & Categories & $\begin{array}{l}\text { Satisfied } \\
\mathrm{N}(\%)\end{array}$ & $\begin{array}{l}\text { Dissatisfied } \\
\mathrm{N}(\%)\end{array}$ & $\begin{array}{l}\text { Chi }\left(x^{2}\right) \\
\text { P-value }\end{array}$ & $\begin{array}{l}\text { Unadjusted Odds Ratio } \\
(95 \% \text { C.I.) }\end{array}$ & $\begin{array}{l}\text { Adjusted odds ratio } \\
\text { (95\% C.I.) }\end{array}$ \\
\hline \multirow[t]{2}{*}{ Sex } & Female & $155(77.1)$ & $46(22.9)$ & \multirow{2}{*}{$\begin{array}{l}2.045 \\
0.153\end{array}$} & 1 & \\
\hline & Male & $120(70.6)$ & $50(29.4)$ & & $0.77(0.426-1.39)$ & \\
\hline \multirow[t]{5}{*}{ Education } & College & $35(59.3)$ & $24(40.7)$ & \multirow{5}{*}{$\begin{array}{l}13.830 \\
0.008\end{array}$} & 1 & 1 \\
\hline & Illiterate & $25(69.4)$ & $11(22.4)$ & & $0.54(0.16-1.89)$ & $1.26(0.48-3.3)$ \\
\hline & Elementary & $53(88.3)$ & $7(11.7)$ & & $3.1(0.97-9.8)$ & $5.45(1.99-15.12)$ \\
\hline & Junior & $45(77.6)$ & $13(22.4)$ & & $1.20(0.45-3.2)$ & $1.86(0.764-4.52)$ \\
\hline & High School & $117(74.1)$ & $41(25.9)$ & & $1.58(0.74-3.4)$ & $1.925(0.956-3.87)$ \\
\hline \multirow[t]{4}{*}{ Age (years) } & & & & \multirow{4}{*}{$\begin{array}{l}0.199 \\
0.328\end{array}$} & $1.013(1.0-1.03)$ & \\
\hline & $25-40$ years & $85(79.4)$ & $22(20.6)$ & & & \\
\hline & $40-60$ years & $81(74.3)$ & $28(25.7)$ & & & \\
\hline & $>60$ years & $33(75.0)$ & $11(30.6)$ & & & \\
\hline \multirow[t]{2}{*}{ Hospital } & Orotta & $210(87.1)$ & $31(12.9)$ & \multirow{2}{*}{$\begin{array}{l}60.721 \\
0.000\end{array}$} & 1 & 1 \\
\hline & Halibet & $65(50)$ & $65(50)$ & & $0.147(0.084-0.26)$ & $0.143(0.84-0.24)$ \\
\hline \multirow[t]{6}{*}{ Occupation } & Student & $20(71.4)$ & $8(28.7)$ & \multirow{6}{*}{$\begin{array}{l}13.538 \\
0.019\end{array}$} & 1 & \\
\hline & Farmer \& Herdsman & $15(75.0)$ & $5(25)$ & & $1.58(0.33-7.67)$ & \\
\hline & Casual Laborer & $52(86.0)$ & $8(13.3)$ & & $1.32(0.36-4.91)$ & \\
\hline & Jobless & $32(71.1)$ & $13(28.9)$ & & $1.04(0.29-3.67$ & \\
\hline & Government workers & $96(65.8)$ & $50(34.2)$ & & $0.764(0.27-2.19)$ & \\
\hline & House wife & $12(16.9)$ & $50(34.2)$ & & $1.053(0.29-3.72)$ & \\
\hline \multirow[t]{2}{*}{ Residence } & Rural & $81(81.8)$ & $18(18.2)$ & \multirow{2}{*}{$\begin{array}{l}4.168 \\
0.041\end{array}$} & 1 & \\
\hline & Urban & 194(71.3) & $78(28.7)$ & & $0.738(0.37-1.45)$ & \\
\hline \multirow[t]{4}{*}{ No. of visit } & Greater than 4Times & $25(62.5)$ & $15(37.5)$ & \multirow{4}{*}{$\begin{array}{l}3.174 \\
0.366\end{array}$} & 1 & \\
\hline & 1Times & $147(75.8)$ & $47(24.2)$ & & $1.170(0.49-2.811)$ & \\
\hline & 2Times & $73(75.3)$ & $24(24.7)$ & & $1.716(0.68-4.323)$ & \\
\hline & 3Times & $30(75.0)$ & $10(25)$ & & $1.53(0.517-4.52)$ & \\
\hline
\end{tabular}

AOR: Adjusted Odds Ratio; COR: Crude Odds Ratio 
In the multivariate analysis, patients from Halibet hospital were less likely to be satisfied with laboratory services $(\mathrm{COR}=$ 0.147(0.084-0.26; $\mathrm{P}<0.000)$. In addition, educational status was significantly associated with likelihood of satisfaction Elementary $(\mathrm{AOR}=5.45(1.99-15.12 ; \mathrm{P}<0.001)$ in the adjusted model. In this analysis, satisfaction rating was significantly associated $(p<0.05)$ with level of education, occupation, residence and hospital. Patients with college level qualification $35(59.3 \%)$ were comparatively less satisfied with laboratory service at the two institutions $(p<0.008)$. laboratory services offered at Orotta hospital had a higher rating 210(87.1\%) compared services to Halibet hospital 65(50\%)(P<0.000).

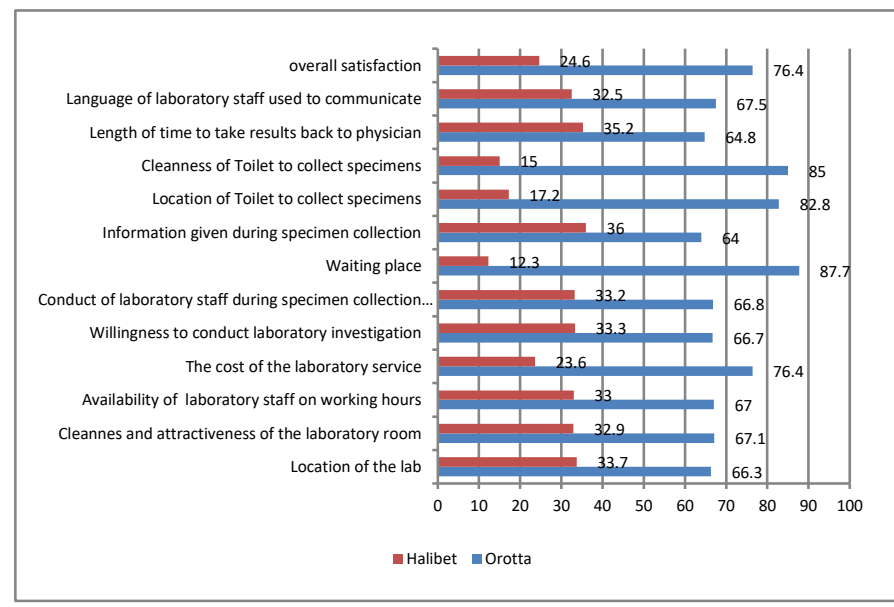

Figure 1: Level of satisfaction of patients at selected hospitals

Analysis of the level of satisfaction in the two institutions was evaluated. In this analysis, the level of satisfaction among patients was higher in Orotta Referral Hospital for all the measured items. The overall satisfaction rating was $24.6 \%$ in Halibet. On the contrary, Orotta had an overall satisfaction rating of $76.4 \%$. Figure 1.

The overall satisfaction of clinicians towards laboratory services is $85.3 \%$. The lowest satisfaction ratings included availability of requested tests $(74.6 \%)$; getting urgent result on time $(74.6 \%)$ critical value notification (79.4\%). Missing laboratory results $(81.4 \%)$ was also flagged as a serious issue by some physicians. Courtesy of laboratory staff received the highest rating (94.9\%). See on supplementary materials(Supplementary Table 2).

\section{DISCUSSION}

Measurement of customer satisfaction brings customer preferences into the quality assessment process and may correct false assumptions about particular aspects of service. In particular, dissatisfaction associated with laboratory service provision may undermine laboratory service utilization and increase physician's turnover or early retirement [2, 11, 12]. This may have negative impact on continuity and quality of health care.

In this study, the overall rate of satisfaction by patients was 74.1 $\%$. Lower satisfaction ratings have been reported in other settings in the region - 59.7\% at Tikur Anbessa Specialized hospital in Addis Ababa ${ }^{[13]}$. Conversely, a study conducted at a student run medical clinic in Ethiopia reported a mean satisfaction rating of $4.41^{[14]}$. However, the percentage of satisfaction was similar to a study on laboratory services in antiretroviral therapy clinics in Addis Ababa, Ethiopia ${ }^{[15]}$. Higher rates of patient's satisfaction were on the availability of laboratory staff during working hours and willingness to conduct laboratory investigations. A lower rating was obtained on provision of appropriate information to patients. Several factors may be invoked to explain the observed disparities including differences in age of the institution (design requirement for modern hospital are different); institutional culture; funding and staffing disparities.

The relationship between level of satisfaction and specific institutional and demographic factors was also explored. In this analysis, we noted that patients from Halibet hospital were less likely to be satisfied with laboratory services offered at the institution. The association between educational status and level of satisfaction is unique as it differs from other reports [16, 17]. A plausible explanation for the observed difference is largely unclear. Multivariate modelling also demonstrated a connection between hospital and level of satisfaction. The wide disparity in satisfaction rating between the two hospitals may be due to several administrative factors including service prioritisation. In particular, the connection between basic infrastructure differences and level of satisfaction corroborates reports from a study in Ethiopia [18]. In this study, cleanness and location of toilets (difficulty associated with locating specimen collection point like toilets) had the lowest satisfaction rating. These findings emphasises the significance of all laboratory environments on client satisfaction. Therefore, location of laboratory toilet should be a key factor in hospital design.

The lowest satisfaction for clinical service providers included availability of requested tests, turnaround time for results on emergency cases and missing results. Malfunction of equipment and shortage of basic consumable reagents may explain some of these findings.

\section{CONCLUSIONS}

Although the overall level of satisfaction was high, this study identified considerable room for improvement in several indicators including services such as waiting area, the cleanness of latrines, information given during specimen collection outside laboratory and cost of laboratory services. The practice standards set by the Eritrean $\mathrm{MOH}$ should also be set based on needs assessment considering all stakeholders including patient needs so that the cost of setting up a laboratory considers the cost of patient service requirements. To these end, the need to relate the effectiveness of clinical laboratory services and evidence-based quality indicators will be paramount.

\section{Limitations}

This study has several limitations. First, the study used selfreported questionnaires which are generally subject to response biases. Rating of satisfaction level was also subjective. Moreover, the study was limited to two referral hospitals in Asmara. Therefore, generalization of the findings to other facilities within the country may be inappropriate.

\section{Abbreviations}

AIDS: Acquired Immunodeficiency Syndrome; HIV: Human Immunodeficiency Virus; $\mathrm{MCH}$ : Maternal and Child Health; OPD: Out Patient Department; SPSS: Statistical Package for Social Sciences; WHO: World Health Organization; HCSDD: Health Care Service Delivery Division 


\section{Declarations}

\section{Ethical approval and consent to participate.}

Ministry of Health Eritrea and research ethical committee approved the study.

\section{Consent for publication.}

Not applicable

\section{Availability of Data and Materials.}

Not applicable.

\section{Competing interest}

All the authors declare that they have no conflict of interest associated with the publication of this manuscript.

\section{Funding}

This research did not receive financial support from external source, it was self-financed by the authors.

\section{Authors contribution.}

$\mathrm{FH}$ and EG designed the study, collected, analyzed, interpreted the data and drafted the manuscript. YT participated in data collection, designing of the study and write up of the proposal. AT and SN contributed significantly in collecting data, advising, editing, reviewing of both the proposal and manuscript.

\section{Acknowledgement}

The authors sincerely appreciate stakeholders in Eritrea Ministry of Health, Medical directors and Head of laboratory in Orotta and Halibet Hospital, all laboratory staffs especially the phlebotomy sections staffs for the support and providing a conducive atmosphere for the successful conduct of this study.We would like to thank Andeberhan Teweldefrom monitoring and evaluation division of ministry of health for the support in sample size determination.

\section{REFERENCES}

1. Teklemariam Z, Mekonnen A, Kedir H, and Kabew G. Clients and clinician satisfaction with laboratory services at selected government hospitals in eastern Ethiopia. BMC Research Notes. 2013. 6(15).

2. Jones BA, Bekeris LG, Nakhelh RE, Walsh MK, Valenstren PN Physician satisfaction with clinical laboratory services. College of American Pathologist Q-Probes study of 138 institutions. Arch Pathol Lab Med, 2009; 133:38-43.

3. Emilia Georgieva, Gabriela Tsankova, Violina Kaludova, NeliErmenlieva. Patients 'Satisfaction with Laboratory Services at Selected Medical - Diagnostic Laboratories in Varna. Journal of IMAB- Annual Proceeding. 2014; 2(2).

4. Belay M, Abrar S, Bekele D, Daka D, Derbe M, Birhaneselassie M. HIVIAIDS patients' satisfaction on ART laboratory service in selected governmental hospitals, Sidamma Zone, Southern Ethiopia. Sci J Pub Health. 2013; 1(2):85-90.

5. Raheem AR, Nawaz A, Fouzia N, Imamuddin K. Patients' satisfaction and quality health services: an investigation from private hospitals of Karachi, Pakistan. Res J Recent Sci. 2014 3(7):34-38.

6. Sodani PR, Kumar RK, Srivastava J, Sharma L. Measuring patient satisfaction: a case study to improve the quality of care at public health facilities. Indian J Community Med. 2010; 35(1):52-56.

7. Dawar R. Patient satisfaction of phlebotomy services in a tertiary care hospital. Int J Curr Res Aca Rev. 2015; 3(6):35-38.

8. Woldeyohanes TR, Woldehaimanot TE, Kerie MW, Mengistie MA, Yesuf EA. Perceived patient satisfaction with in-patient services at Jimma University Specialised Hospital, South West Ethiopia. BMC Res Notes (2015) 8:285DOI 10.1186/s13104-015-1179-8.

9. Piang L, Tiwari V, Nair K, Raj S, Kaur H, Gandotra R. Patient's satisfaction with quality of services providers at the tertiary care cancer hospitals in India. Indian J Prev Soc Med. 2012; 43(4):396404.

10. Survey Methods and Practices Statistics Canada, 2010.

11. N. Mujahed Adulkader and B.E. Garcia Triana. Physician satisfaction with hospital clinical laboratory services in Aden Governorate, Yemen, Eastern Mediterranean Health Journal, 2009; 19(6):555-560.

12. Regional Committee for Africa, WHO (2008). Strengthening public health laboratories in the WHO African region: a critical need for disease control. Fifty-eighth session, Yaounde, Republic of Cameroon. agoiheo

13. Rodas Getachew Abera, Boaz ArkaAbota, Melese Hailu Legese and Abeba Edao Negessos patient satisfaction with clinical laboratory service at Tikur Anbessa Specialzed Hospital, Adiss Ababa, Ethiopia. Dove press journal 12july 2017

14. Ellet JD, Campbell JA, Gonsalves WC. Patient satisfaction in a student run free medical clinic. [pub Med]Fam.Med. 2010; 42(1):16-8.

15. TedlaMindaye and Bineyam Taye Patienta satisfaction with laboratory service at antiretrovral therapy clinincs in public hospital, Adiss Ababe, Ethiopia BMC Research Notes 2012; 5(1):184.

16. Zelalem Teklemariam, AbiyuMekonnen and Haji Kedir and Getachew Kabew. Clients and clininciansatsfaction with laboratory services at selected government hospitals in eastern Ethiopia. BMC Research Notes, 2013; 6:15.

17. Muhondwa EPY, Leshabari MT, Mwangu M, Mbembati N, Ezekiel MJ. Patient satisfaction at the Muhimbili National Hospital in Dar Es salaam, Tanzania. East Afr J Public Health, 2008; 5(2):67-73.

18. Geletta Tadele, Eyasu Ejeta,,Mikias Desalegn, Shibabew Abera and Keneni Elias Patients Satisfaction on Clinical Laboratory Service at Nekemte Referral Hospital,Oromia,Ethiopia. Food Science and Quality Management, 2014 vol.30. 